\title{
DETERMINATION OF THE BEST GEOSTATISTICAL METHOD FOR CLIMATIC ZONING IN IRAN
}

\author{
PIRI, I. ${ }^{1}-$ KhANAMANI, A. ${ }^{2}-$ ShOJAEI, S. ${ }^{3}-$ FATHIZAD, H. ${ }^{4 *}$ \\ ${ }^{1}$ Department of Agriculture, Payame Noor University, Iran \\ (e-mail:shojaeisaeeds@gmail.com) \\ ${ }^{2}$ Young Researcher and Elite Club, Jiroft Branch, Islamic Azad University, Iran \\ (e-mail:khanamani@gmail.com) \\ ${ }^{3}$ Young Researcher and Elite Club, Zahedan Branch, Islamic Azad University, Iran \\ (e-mail: s_shojaei@ut.ac.ir) \\ ${ }^{4}$ Department of Natural Resources and Desert Studies, Yazd University, Yazd, Iran \\ (e-mail: hasan.fathizad@gmail.com) \\ ${ }^{*}$ Corresponding author \\ hasan.fathizad@gmail.com \\ (Received $5^{\text {th }}$ Jul 2016; accepted $10^{\text {th }}$ Oct 2016)
}

\begin{abstract}
Zoning using climatic indices is of significant value in climate studies and climate- related planning. The aim of this study is to assess De Martonne aridity index and to select the best model to draw Iran's complete map based on 150 station's temperature and precipitation data over a 25 -year period (1986-2010). Kolmogorov - Smirnov test (K-S test) was used to check the normality of the data. In order to assess De Martonne aridity index, annual temperature and precipitation data were collected from properly-distributed stations in the study period. Using De Martonne aridity index formula, this index was calculated for all the stations. In the next step, using different geostatistical methods, De Martonne aridity index map was drawn. Semivariogram was used to show the spatial correlation between aridity index data in which linear semivariograms of 0.84 was the best interpolation model to show the correlation. To estimate De Martonne aridity index, inverse distance weighting (IDW), global polynomial interpolation (GPI), radial basis function (RBF), local polynomial interpolation (LPI), as well as Kiriging methods were used. Root mean square error (RMSE), and mean absolute error (MAE) were used to select the best interpolation method. Our results showed that simple kriging method shows the highest correlation with the observed data $(\mathrm{R} 2=0.77)$. Moreover, it is shown that Iran's central regions due to locating in low lands and being far from the northern and western mountain ranges (Alborz and Zagros) has the lowest De Martonne aridity index $(<5,5-10)$ and is classified as arid and semi-arid areas while Iran's northern regions has the highest De Martonne aridity index (> 55) is classified as very humid area showing a wide climate range of arid to very humid in Iran.
\end{abstract}

Keywords: GIS, rainfall, interpolation, temperature, semivariogram

\section{Introduction}

Aridity which is defined as the lack of moisture is a climatic phenomenon that is based on the average climatic conditions of a consistent region (Tabari et al., 2014). Increased aridity and subsequent desertification, is one of the environmental problems that affect people's living conditions in the world's arid areas. Paying attention to different climatic regions and its understanding is quite essential. Understanding climatic condition is the most essential step in studying different human activities such as agriculture, environment, urban planning, transportation, tourism, etc., (Adnan and Haider, 2012). Climatic parameters are useful tools to characterize the status of the climatic system and to perceive its different involving mechanisms (Deniz et al., 2011). 
Aridity index is a climatic index that can be used to monitor and predict aridity (Nastos et al, 2013). So far, several climatic indices have been developed and used utilized in order to study the climatic condition of various regions among which Emberger, Torrent White (Alizadeh et al., 2001), De Martonne., etc. can be mentioned (Tabari et al., 2014). Determination of the most suitable interpolation method in an area and explanation of its spatial distribution is necessary to estimate the spatial distribution of the climatic parameters. There are various methods to assess and estimate such parameters. All these methods are computationally fast and easy. For example, the classical methods, such as Thiessen and the arithmetic mean can be mentioned. There are several methods to estimate the spatial data among which the most common ones include arithmetic mean, gradient, and Thiessen (Corwin et al., 1992; Hosseini et al., 1993). But for some reasons such as not considering the spatial data, and correlation between observations, such methods are not sufficiently accurate. Of course, there are other methods that due to consideration of the spatial correlation of data are highly significant. Deficiencies of the mentioned methods specify the necessity of using geostatistical methods. Geostatistical methods due to considering the spatial correlation of data are of particular importance in assessment of the spatial distribution of the geological data, and gives a better estimate of the underlying parameter in the areas that are not sampled yet (Karimi Nazar et al., 2009). One of the currently used alternative methods to the classical statistical methods (such as regression, weighted inverse square distance, etc.) is the geostatistical methods. Nowadays, these methods are used for interpolation of rainfall stations and other spatial variables (Shabani et al., 2011). Many researchers have been involved in comparison and assessment of various interpolation methods which represents the importance of this issue to reduce the errors of method selection. To interpolate the annual rainfall and temperature in an area of five thousand square kilometers in Portugal, Goovaerts (2000) considered simple kriging method more appropriate as compared to inverse-square method, linear regression with height, Thiessen and kriging methods. Tabari et al. (2014) used data from 40 stations in a time period of 1965 to 2005 to assess De Martonne aridity index. Using the ordinary kriging climate zoning method, these researchers concluded that $88 \%$ of Iran involves arid and hyper-arid areas. Furthermore, De Martonne aridity index was decreased by $18 \%$ to 54 $\%$ in the western and north-western areas. The aim of this study was climate zoning and assessment of De Martonne aridity index using a variety of geostatistical methods and data from 150 rainfall stations in Iran. The aridity index De Martonne modeling was carried out using Arc GIS 9.3 and $\mathrm{GS}^{+}$softwares.

\section{Materials and methods}

\section{Study area}

Iran, with an area of 1648195 square kilometers has been located between latitude of $25^{\circ}$ to $40^{\circ} \mathrm{N}$ and longitude of $44^{\circ}$ to $63^{\circ} \mathrm{E}$ (Fig.1). So in terms of latitude southern parts are located in tropical areas, and northern parts are located in subtropical regions. Iran has different climatic conditions due to its geographical position which means fifteen degrees' latitude dispute between the most southern and the most northern point, as well as folds and ups and downs that can be observed on its surface. Apart from these two factors, the combination of the air masses that originate from different regions and collide on Iranian plateau, is one of the most important factors to determine Iran's climatic conditions. Proximity to the Persian Gulf and Oman Sea on one side and the 
impact of the Mediterranean Sea on the other side, along with the presence of dry deserts of Arabia and Africa and northeastern great Siberian Plain is effective on type of the air masses that reach Iran.

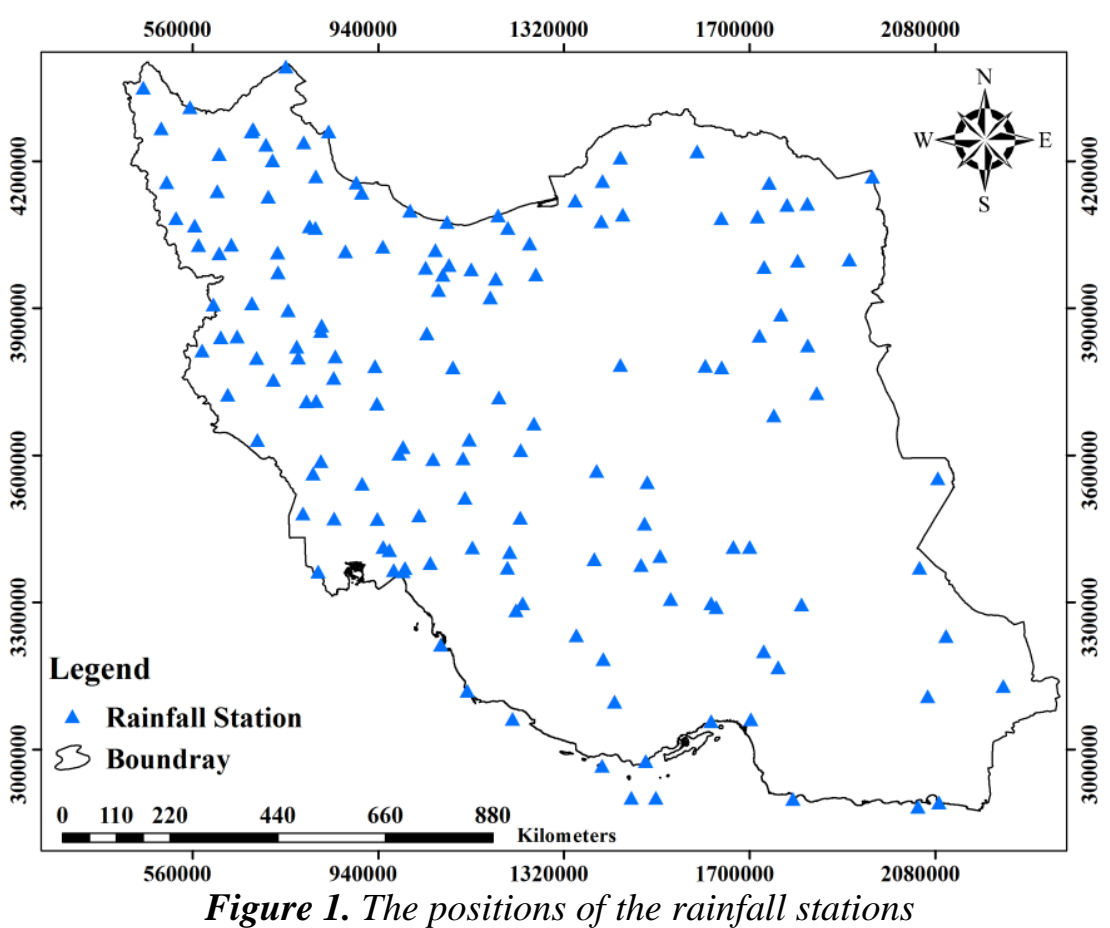

\section{Statistical analysis}

Kolomograve - Smirnov test was used to evaluate the normality of the data in the present study. Rainfall data were used following normalization. The histogram (Figure 2) and the statistical analysis of De Martonne aridity index from 150 stations in the study area over a period of 25 years (1985-2009) was analyzed in SPSS V.21 software. The results are presented in Table 1. Figure 1 shows the positions of the rainfall stations.

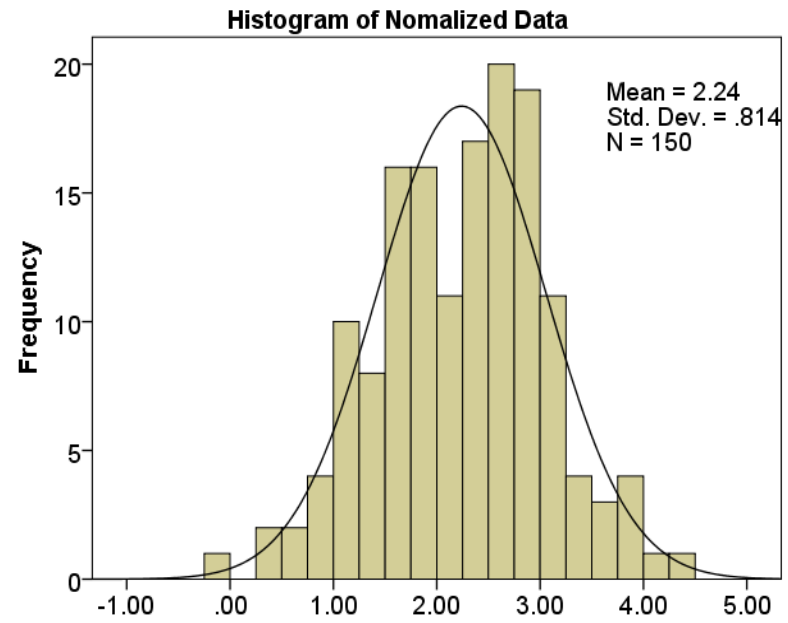

Figure 2. Histogram of the normalized De Martonne aridity index 
Table 1. Statistical analysis of the data from the study area

\begin{tabular}{|c|c|c|c|c|c|c|c|c|}
\hline maximum & minimum & skewness & variance & mode & $\begin{array}{c}\text { standard } \\
\text { deviation }\end{array}$ & $\begin{array}{c}\text { the mean } \\
\text { standard } \\
\text { error }\end{array}$ & mean & parameter \\
\hline 71.26 & 0.82 & 2.42 & 134.56 & 3.34 & 11.60 & 0.94 & 12.93 & value \\
\hline
\end{tabular}

\section{De Martonne aridity index (I)}

De Martonne climate classification is one of the conventional methods in climate classification which is used in most climatology projects, particularly in dam construction, agriculture, etc. The basis of this method is presented in Equation (1) and Table 2 (Tabari et al., 2014).

$$
I=\frac{P}{T+10}
$$

Where $\mathrm{P}$ is the average annual rainfall in $\mathrm{mm}, \mathrm{T}$ is the average annual temperature in Celsius, and I is De Martonne aridity index.

Table 2. De Martonne aridity index climate classification (Tabari et al., 2014)

\begin{tabular}{|c|c|}
\hline $\mathbf{I}_{\mathrm{DM}}$ value & Climatic condition \\
\hline $\mathrm{I}_{\mathrm{DM}}<5$ & Hyper- arid \\
\hline $5<\mathrm{I}_{\mathrm{DM}}<10$ & arid \\
\hline $10<\mathrm{I}_{\mathrm{DM}}<20$ & Semi- arid \\
\hline $20<\mathrm{I}_{\mathrm{DM}}<24$ & Mediterranean \\
\hline $24<\mathrm{I}_{\mathrm{DM}}<28$ & Sub-humid \\
\hline $28<\mathrm{I}_{\mathrm{DM}}<35$ & humid \\
\hline $35<\mathrm{I}_{\mathrm{DM}}<55$ & Very humid \\
\hline $55<\mathrm{I}_{\mathrm{DM}}$ & Extremely humid \\
\hline
\end{tabular}

Therefore, annual rain falls and temperature data from 150 rain stations in a time period of 1985 to 2009 were extracted. Statistical analysis was carried out in SPSS V.21. De Martonne aridity index for each station was calculated according to equation I in Excel 2013. The best geostatistical method for climate zoning was selected using Arc GIS V.9.3 software.

\section{Geostatistical analysis}

Geostatistics according to the simplest definition is an interpolation method in which the interpolation index or estimation is the minimization of estimation variance (Hohn, 1998). Interpolation is actually the estimation of continuous unknown variable based on a known sample in the region (Lu and Wong, 2008). Geostatistical estimation is one of the most accurate estimation method, since it examines several factors including the distance between points, anisotropy, and spatial variability. But this method has a high volume of calculations that increases the calculation time in large operations (Hirsche et al., 1998). Geostatistics is the study of phenomena which vary in space and time. It 
deals with analysis of samplings with different positions in order to make a continuous level (Johnston et al., 2001). Geostatistical analysis is looking for a way to characterize the spatial continuity and to collect statistical tools and to model such changes. The basic assumption of this spatial- statistical analysis is that nearby observations as compared to distant observations show more statistical correlation. It should be mentioned that the possibility of achieving accurate and efficient results through this type of analysis, is achieved when data are normally distributed and possibly fixed and their mean and variance do not vary spatially (Bohling, 2005).

\section{Variogram}

Geostatistics is used to determine the spatial structure of the variables by the average of probabilistic models. This spatial structure is characterized by variogram (ZamaniAhmad Mahmoodi et al., 2014). Actually variogram is the first step to model spatial structure for Kiriging method. The main aim of semivariogram establishment is to be able to characterize the structure of variable based on the spatial distance. Variogram is calculated using the following equation (Webster and Oliver, 2000: 56):

$$
\gamma(h)=\frac{1}{2 n(h)} \sum_{i=1}^{n(h)}\left[z\left(x_{i}\right)-z\left(x_{i+h}\right)\right]^{2}
$$

Where, $\gamma(\mathrm{h})$ is semivariogram for a pair of points that are located with $\mathrm{h}$ distance from each other, $\mathrm{n}$ is the number of pair of points that are located with distance $\mathrm{h}$ from each other, $\mathrm{z}$ (xi) is the observed value for the variable in point $\mathrm{X}$, and $\mathrm{z}(\mathrm{xi}+\mathrm{h})$ is Observed value for the variable with distance $\mathrm{h}$ from $x$ (Webster and Oliver, 2000: 56). In variogram curve with increasing distance (h), the amount of $\gamma(\mathrm{h})$ increases, and this situation will continue until a certain distance from which the value remains constant. In the present study, De Martonne aridity index was estimated using different interpolation methods including inverse distance weighting (IDW), global polynomial interpolation (GPI), radial basis function (RBF), local polynomial interpolation (LPI), as well as Kiriging methods.

\section{Results}

Variogram was used to show the spatial correlation between De Martonne aridity index data. The results are presented in Fig.3. Then variogram Y (h) was used to fit the data as it shows the spatial correlation between observed De Martonne aridity index data better than other variograms. For this matter the ratio between the nugget effect and sill was used $(\mathrm{Co}+\mathrm{C})$ ( $\mathrm{Li}$ et al., 2015). If the value is $<0.25$ it indicates high spatial correlation, if the value is in the range of $0.25-0.75$ it indicates medium spatial correlation, and if the value is $>0.75$ it shows either low spatial correlation or no spatial correlation between data (Khodakarami et al., 2011). 

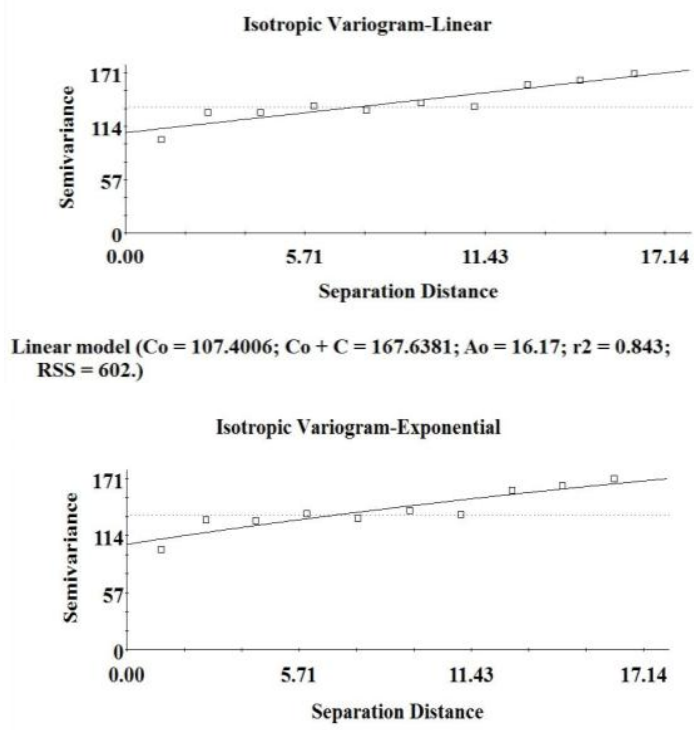

Exponential model $\left(\mathrm{C}_{0}=105.2000 ; \mathrm{C} 0+\mathrm{C}=272.5000 ; \mathrm{A0}=36.11 ; \mathrm{r} 2=0.837\right.$ RSS $=625$.)

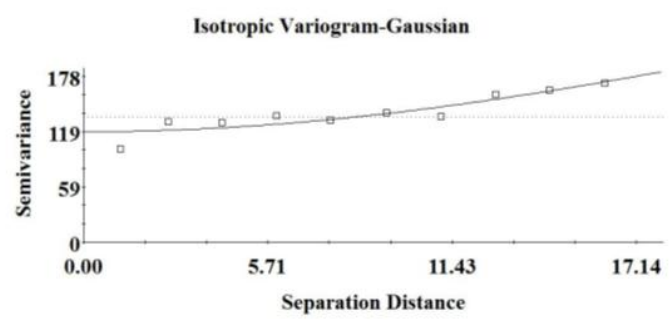

Gaussian model $\left(\mathrm{Co}_{0}=118.7000 ; \mathrm{Co}+\mathrm{C}=389.4000 ; \mathrm{Ao}=34.38 ; \mathrm{r} 2=0.816\right.$; RSS $=$ 708.)

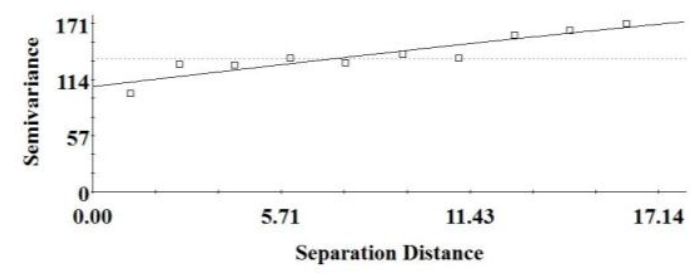

Spherical model $(\mathrm{Co}=106.7000 ; \mathrm{Co}+\mathrm{C}=213.6000 ; \mathrm{Ao}=40.96 ; \mathrm{r} 2=0.840$ RSS $=616$.)

Figure 3. Variogram to fit De Martonne aridity index data

Therefore, this ratio was used to select the best variogram. Based on the obtained parameters for the variogram Y (h), linear variogram with the ratio of the 0.83 modeled the best correlation between data and was used as the best interpolation method. Following linear variogram, Gaussian, spherical, and exponential variograms are placed with the amount of $0.82,0.84$, and 0.83 , respectively. Different types of the applied variograms to fit data are presented in Table 3.

Table 3. The nugget effect and sill obtained for the fitted variograms

\begin{tabular}{|c|c|c|c|c|c|}
\hline Model type & $\begin{array}{c}\text { Nugget effect } \\
\left(\mathbf{m m}^{2}\right) \mathbf{C o}\end{array}$ & $\begin{array}{c}\text { Sill } \mathbf{( m m}^{\mathbf{2}} \mathbf{\text { Co+C }} \\
\mathbf{C o}\end{array}$ & $\begin{array}{c}\mathbf{C} / \mathbf{C o}+\mathbf{C} \\
\text { ratio }\end{array}$ & $\begin{array}{c}\text { Distance } \\
(\mathbf{k m}) \mathbf{A o}\end{array}$ & $\mathbf{R}^{\mathbf{2}}$ \\
\hline Gaussian & 118 & 389 & 0.69 & 34 & 0.81 \\
\hline Linear & 107 & 167 & 0.35 & 16 & 0.84 \\
\hline spherical & 106 & 213 & 0.50 & 40 & 0.84 \\
\hline exponential & 105 & 272 & 0.61 & 36 & 0.83 \\
\hline
\end{tabular}

The results on different models evaluation is presented in Table 4. Our results showed the highest correlation between simple- kriging method and the observed data (R2=0.77).

Table 4. De Martonne aridity index data correlation based on different statistical methods

\begin{tabular}{|c|c|c|c|}
\hline Method & Linear & Power & Exponential \\
\hline Emprical & 0.54 & 0.70 & 0.46 \\
\hline LPI_1 & 0.53 & 0.69 & 0.45 \\
\hline LPI_2 & 0.54 & - & - \\
\hline LPI_3 & 0.54 & - & - \\
\hline
\end{tabular}




\begin{tabular}{|c|c|c|c|}
\hline GPI_1 & 0.23 & - & - \\
\hline GPI_2 & 0.22 & - & - \\
\hline GPI_3 & 0.25 & - & - \\
\hline IDW_1 & 0.43 & 0.63 & 0.37 \\
\hline IDW_2 & 0.42 & 0.66 & 0.42 \\
\hline IDW_3 & 0.41 & 0.66 & 0.43 \\
\hline RBF & 0.50 & 0.70 & 0.45 \\
\hline K_O_Ga & 0.55 & 0.73 & 0.48 \\
\hline K_O_St & 0.55 & 0.73 & 0.48 \\
\hline K_Si_Ga & 0.57 & 0.69 & 0.45 \\
\hline K_Si_St & 0.57 & 0.69 & 0.45 \\
\hline K_Si_Ex & 0.72 & 0.77 & 0.56 \\
\hline K_Si_Sp & 0.65 & 0.73 & 0.50 \\
\hline K_Un_Ga & 0.55 & 0.72 & 0.47 \\
\hline K_Un_St & 0.55 & 0.72 & 0.47 \\
\hline
\end{tabular}

Q-Q Plot of the original and normalized data in SPSS V.21 is presented in Fig.4. The plot representing the observed and predicted De Martonne aridity index data using simple - kriging method is presented in Fig.5.
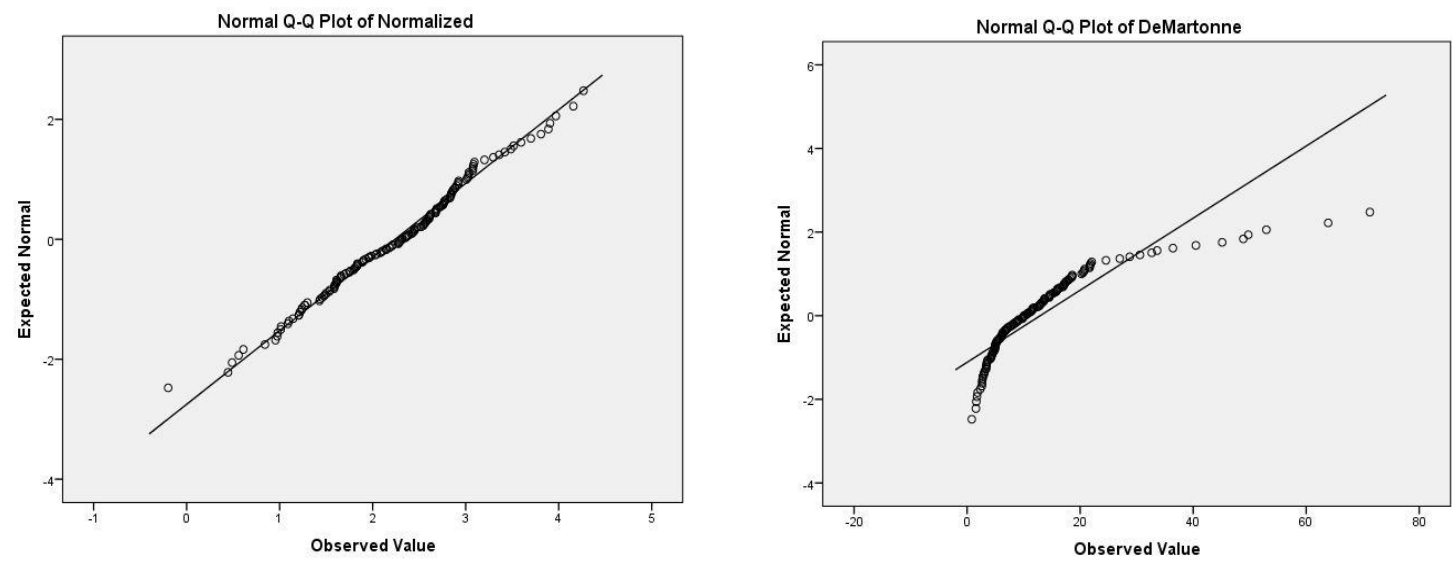

Figure 4. $Q-Q$ Plot of the original (right side), and normalized (left side) De Martonne aridity index data.

Fig.6. represents the zoning map of De Martonne aridity index using the simplekriging method which shows the highest statistical accuracy than other methods. Because of the high number of stations in the area and their appropriate distribution, a complete zoning map of the area can be prepared. Also Figure 6 represents the map of the difference between the average maximum and minimum temperature $(\Delta \theta)$, average maximum and average minimum temperature. It was statistically predicted that a high correlation may be observed between $\Delta \theta$ and De Martonne aridity index, however, this correlation was very low at the level of approximately $10 \%$. Comparison of $\Delta \theta$ and De Martonne aridity index maps showed a high correlation between these parameters on their maps, so that in the central and eastern parts of the country with the lowest De Martonne aridity index, $(\Delta \theta)$ shows the highest value. Furthermore, as we getting 
closer to the northern strip of the country, De Martonne aridity index is increased, while $(\Delta \theta)$ is decreased. Unlike the central and northern strip of the country, a good spatial correlation is not observed between these two indices in the west and south of the country. Because of the low rainfall in the southern strip, De Martonne aridity index is also low, but because of the proximity to the sea as a source of moderating temperatures and also proximity to the equator, the difference between the minimum and maximum average temperature is not too much. Also, due to the high rainfall in the west of the country, De Martonne aridity index is high, and the temperature difference is too much.

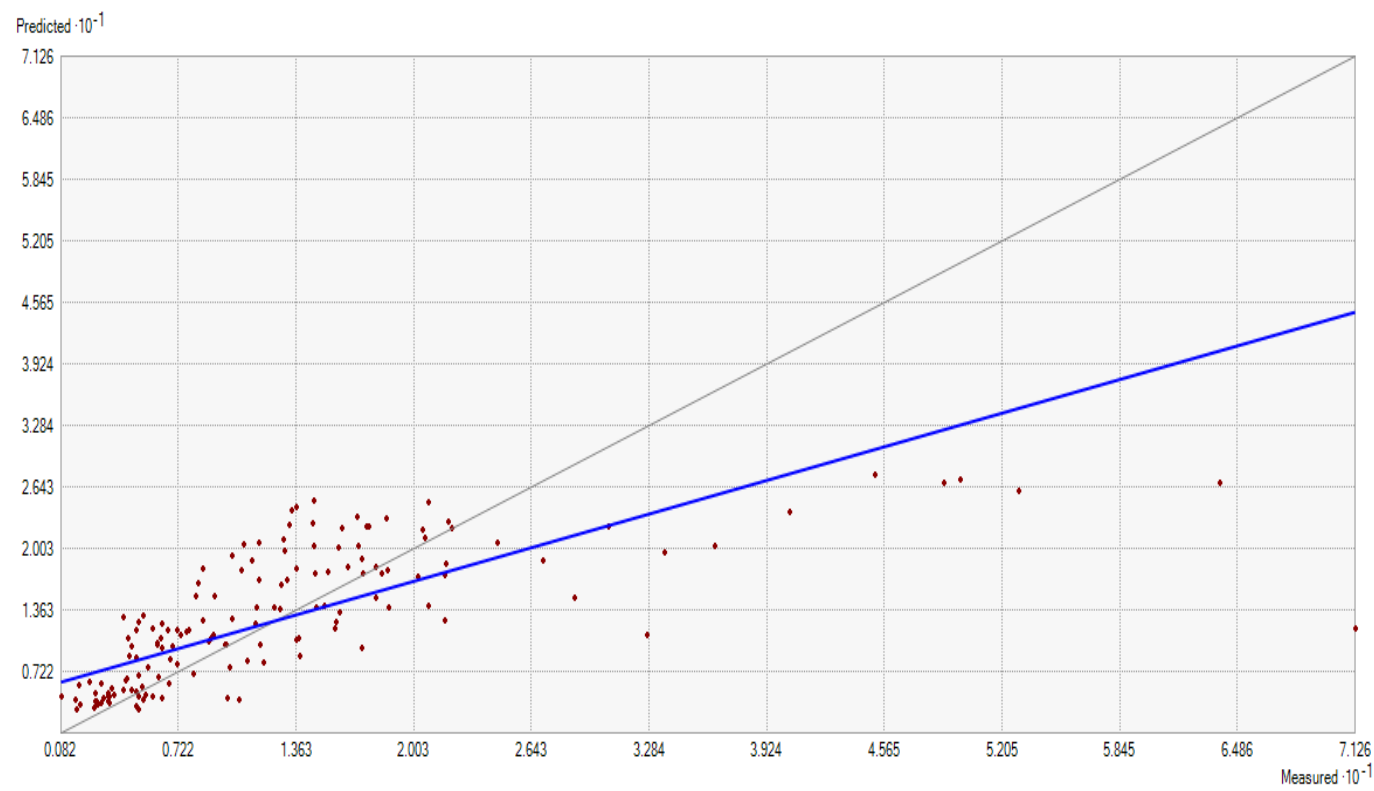

Figure 5. Assessment of the relation between the observed and predicted De Martonne aridity index data using simple - kriging method.
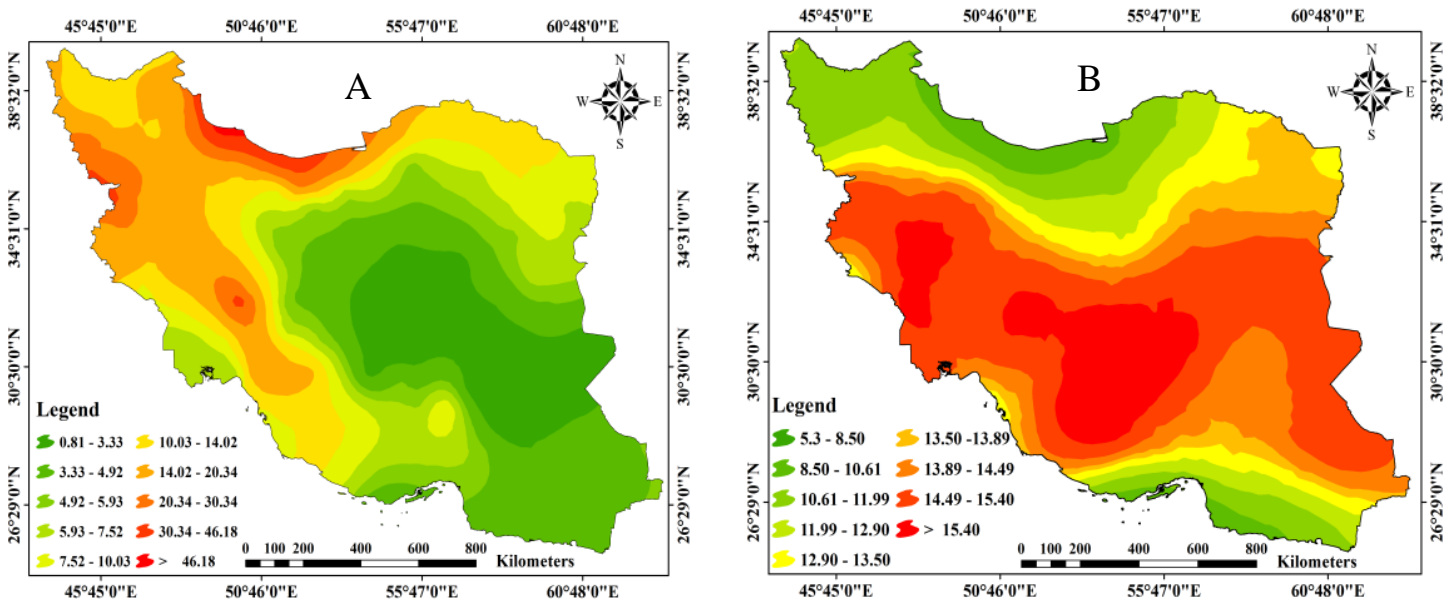

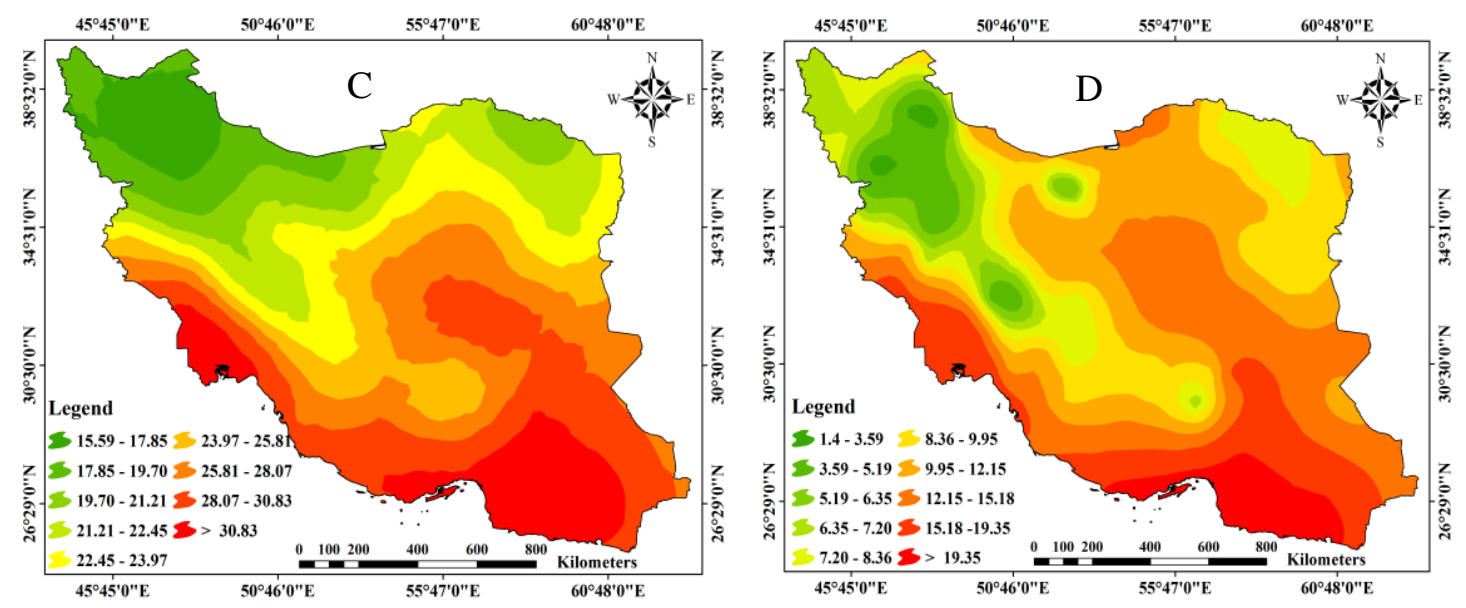

Figure 6. Map of De Martonne Aridity index (A), difference between the average maximum and minimum temperature $(\Delta \theta)(B)$, average maximum temperature $(C)$ and average minimum temperature $(D)$

In the present study, 17 interpolation methods including IDW, GPI, RBF, LPI, as well as Kiriging was used to assess De Martonne aridity index in Iran. Variogram used in this study clearly showed that semivariograms besides demonstration of the spatial correlation between De Martonne aridity index data are able to model the changes in the spatial correlation in various aspects. Our results showed the highest correlation between Simple-Kriging method and the observed De Martonne aridity index data. Furthermore, it was shown that linear variogram with the nugget effect /sill ratio of the 0.83 modeled the best correlation between observed De Martonne aridity index data and was used as the best interpolation method. Following linear variogram, Gaussian, spherical, and exponential variograms are placed with the amount of $0.82,0.84$, and 0.83 , respectively. Moreover, the relation between the observed and predicted De Martonne aridity index data (R2=0.77) was assessed to validate data (Fig.5). The strong correlation between the observed and expected data shows high performance of SimpleKriging method as the interpolation method in the present study. Musburger et al. (2012) used the correlation between the observed and predicted data $(\mathrm{R} 2=0.69)$ to validate the data series.

\section{Conclusion}

Interpolation of data along with GIS is of particular importance in spatial analysis, since many of the maps used in GIS operations are provided through interpolation. In fact, providing continuous models from spatial and temporal distribution of data is possible through interpolation. De Martonne aridity index is a linear relationship, and as it has a direct relation with rainfall value, the classification of this index is highly correlated with rainfall value (R2=0.96). The lowest De Martonne aridity index belongs to central, eastern and south-eastern areas which are actually Kavir plain (central Iran) and Lut plain (Southeast). Getting away from these areas in all geographical directions, the aridity is decreased, and as a result De Martonne aridity index is increased. The highest De Martonne aridity index is observed in northern areas, next to the Caspian Sea. Astara with the mean annual rainfall of $2000 \mathrm{~mm}$ is located in this area (40 times 
more than the mean annual rainfall of the central areas). Iran's climate is highly affected by the presence of the Alborz and Zagros Mountains. Alborz Mountains, particularly its northern slopes devote a high portion of the northern rainfall to itself and prevents the passage of the northern stream to the central areas. Zagros Mountain which is located in north-west /south-east direction devotes the Mediterranean rainfall to it and prevents the rainfall to be passed to the central parts. As a result, a vast part of central areas in Iran has an arid and semi-arid climate.

Other factors which contribute to the excessive dryness of these areas include being away from the moisture sources and being placed in high pressure mid-latitudes. The major factors that can affect climate classification within a country are topography and mountain as other factors such as being away from the moisture sources and being placed in high pressure mid-latitudes are fixed for a country.

\section{REFRENCES}

[1] Adnan, S., Haider, S. (2012): Classification and Assessment of Aridity in Pakistan by Using Different Aridity Indices. ftp://ftp.wmo.int/Documents/PublicWeb /arep/Weather_Mod_Bali/ENV\%20bruntjes.chalon/ENV.Adnan_Pakistan_paper1.pdf. Accessed 2012.

[2] Alizadeh, A. (2002): Principles Applied Hydrology. Fourth Edition. - Institute Press Astan Quds Razavi. Mashhad.

[3] Bohling, G. (2005): Introduction to GeoStatistics and Variogram Analysis - Kansas Geological Survey, http://people.ku.edu/ gbohling/cpe940/Variograms.pdf , Accessed 2016.

[4] Ferro, V., Giordano, G., Lovino, M. (1991): Isoerosivity and erosion risk map for Sicily. - Hydrol. Sci. J. 36:549-564.

[5] Corwin, D. L., Sorensen, M., Rhoades, J. D. (1992): Using GIS to locate salinity on irrigated soils. - Proc. 8th Conf. Computing in Civil Engineering in Conjunction with A/E/C system '92, TCCP/ASCE-Dallas, TX, June 7: 468-485.

[6] Deniz, A., Toros, H., Incecik, S. (2011): Spatial variations of climate indices in Turkey. International Journal of Climatology 31: 394-403. ftp://ftp.wmo.int/Documents/PublicWeb/arep/Weather_Mod_Bali/ENV\%20bruntjes.chal on/ENV.Adnan_Pakistan_paper1.pdf

[7] Goovaerts, P. (2000): Geostatistical Approach for Incorporating Elevation into Spatial Interpolation Rainfall. - Journal of Hydrology 228:129-133.

[8] Hirsche, K., Boerner, S., Kalkomey, C., Gastaldi, C. (1998): Avoiding pitfalls in geostatistical reservoir characterization: A survival guide. - The leading Edge 17: 493504.

[9] Hohn, M. E. (1998): Geostatistics and petroleum geology. - Kluwer Academic Publisher, Netherlands.

[10] Hosseini, E., Gallichand, J., Caron, J. (1993): Comparison of several interpolators for smoothing hydraulic conductivity data in southwest Iran. - ASAE 36: 1687-1693.

[11] Johnston, K., Ver Hoef, J. M., Krivoruchko, K., Lucas, N. (2001): Using Geostatistical Analyst. - Environmental Systems Research Institute, Inc (ESRI).

[12] Kariminazar, M., Fakhireh, A., Feiznia, S., Rashki, A., Miri Soleyman, S. J. (2009): Assessment of some geostatistics methods for evaluation of wind erosion threshold velocity in Sistan plain. - Journal of Range and Watershed Management (Iranian Journal of Natural Resources) 62 (3): 405-417.

[13] Khodakarami, L., Soffianian, A. R., Mohamadi Towfigh, E., Mirghafari, N. A. (2011): Study of heavy metals concentration Copper, Zinc and Arsenic soil using GIS and RS techniques (Case study: Kaboudarahang, Razan and Khonjin- Talkhab catchment in 
Hamedan province). - Journal of Applied RS \& GIS Techniques in Natural Resource Science 2 (1): 79-89.

[14] Li, H. Y., Webster, R., Shi, Z. (2015): Mapping soil salinity in Yangtze delta: REML and universal kriging (E-BLUP) revisited. - Geoderma 237-238: 71-77.

[15] Lu, G. Y., Wong, D. W. (2008): An adaptive Inverse-Distance Weighting spatial interpolation technique. - Comp. Geosci. 34: 1044-1055.

[16] Meusburger, K., Steel, A., Panagos, P., Montanarella, L., Alewell, C. (2012): Spatial and temporal variability of rainfall erosivity factor for Switzerland. - Hydrology and Earth System Sciences 16: 167-177.

[17] Nastos, P. T., Politi, N., Kapsomenakis, J. (2013): Spatial and temporal variability of the aridity index in Greece. - Atmospheric Research 119: 140-152.

[18] Shabani, A., Matinfar, H. M., Arekhi, S., Rahimi Harabadi, S. (2011): Modeling rainfall erosivity factor using geostatistic techniques (Case study: Ilam Dam Watershed). Journal of Applied RS \& GIS Techniques in Natural Resource Science 2 (2): 55-66.

[19] Tabari, H., Hosseinizadeh Talaee, P., Mousavi Nadoushani, S. S., Willems, P. (2014): A survey of temperature and precipitation based aridity indices in Iran. - Quaternary International 345: 158-166.

[20] Webster, R., Oliver, M. A. (2000): Geostatistics for environmental scientists. -Wiley Press, $271 \mathrm{pp}$.

[21] Zamani Ahmad Mahmmodi, R., Riyahi Bakhtiari, A., Rodriguez Martin, J. A. (2014): Spatial relations of mercury contents in Pike (Esoxlucius) and sediments concentration of the Anzali wetland, along the southern shores of the Caspian Sea, Iran. - Martin Pollution Bulletin 84: 97-103. 